\section{Cellular biology of neurones}

Handbook of Physiology: A Critical, Comprehensive Presentation of Knowledge and Concepts. Section 1: The Nervous System. Vol. 1: Cellular Biology of Neurons, Parts 1 and 2. Edited by J. M. Brookhart, V. B. Mountcastle, E. R. Kandel and S. R. Geiger. Pp. 1717 and 719-1182. (Williams and Wilkins: Baltimore, Maryland, 1977.) $\$ 135$.

IT is almost 20 years since the American Physiological Society began publication of its Handbook of Physiology with three volumes on Neurophysiology. A much needed second edition now makes its appearance with a two-part volume on the Cellular Biology of Neurons. The books were written "to be useful to graduate students and scientists in other fields", and as a result the individual chapters form unusually complete accounts of their various topics, combining the virtues of textbook and review.

The volume opens with a magisterial account of the general morphology of neurones and neuroglia by Palay and Chan-Palay. Synaptic ultrastructure is described in greater detail with some striking freeze-fracture electronmicrographs in the chapter by Heuser and Reese.

The section on excitation and conduction contains an extensive account by Rall of core conductor theory, an understanding of which is essential to an informed interpretation of intracellular potentials. Extracellular potentials are mentioned by Rall, and considered in slightly more detail by Shepherd in his chapter on the olfactory bulb, but the topic does not receive a quantitative treatment in the Handbook, an omission which many will regret. Hille's account of the ionic basis of resting and action potentials is easy to follow, authoritative and reasonably complete, though two important recent developments, the detection of gating currents and the application of noise analysis to excitable membranes, are only briefly mentioned. Constantine covers complementary ground in his chapter on the activation of striated muscle, and is to be congratulated on maintaining his composure while describing the Byzantine complexities of the ionic currents underlying the cardiac action potential. The chapter by Finkelstein and Mauro on physical principles of electrical excitability is among the best in the book, containing a long, hectoring and often brilliantly illuminating account of the thermodynamic basis of the membrane potential.

The section on junctional trans- mission is the longest in the book, with 12 chapters devoted to structure (Heuser and Reese), postsynaptic mechanisms (Takeuchi), presynaptic mechanisms (Martin), electrical transmission (Bennett), smooth muscle and the autonomic nervous system (Holman and Hirst), a group of five chapters on specific transmitters (acetylcholine, the monoamines, and amino acids), neurosecretion (Mason and Bern), and axonal transport (Grafstein). Of these, Bennett's contribution makes the liveliest reading.

The article by Takeuchi in this section is seriously flawed by its imperfect English, something which should have been put right in the editorial office.

Part 2 is concerned with interactions between cells, with chapters on cell culture (Fischbach and Nelson), trophic interactions between nerve and muscle (Rosenthal), specificity of neuronal connections (Grinnell) and glial cells (Orkand) in the opening section. In the next section, Burke and Rudomin provide a comprehensive review of spinal neurones; Shepherd considers the olfactory bulb, with its curious reciprocal dendrodendritic synapses, as a model system for mammalian brain; and in a review of ambitious scope, the late Alden Spencer discusses the physiology of supraspinal neurones.

The final section of the book concentrates on invertebrate nervous systems, with chapters on the organisation of motor systems (Kennedy and

\section{Rockslides and avalanches}

Rockslides and Avalanches. Vol. 1: Natural Phenomena. Edited by B. Voight. Pp. 833. (Elsevier: Amsterdam, New York and Oxford, 1978.) Dfl.240; $\$ 98$.

THE study of rockslides began in Switzerland with the Elm event of 1881 in which a rockslide buried the hamlet of Untertal, destroyed part of the village of EIm and killed 115 people. The canton authorities sent Albert Heim to investigate and he was surprised to discover that the rock debris had actually flowed considerable distances, rather than just fallen.

Of the various descriptive German terms which he used $\mathrm{Hsu}$ proposes that 'sturzstrom' be adopted to denote slides of the type that affected Elm. Analysis of the Elm sturzstrom by $\mathrm{Hsu}$ has shown that the accepted deas of aircushion movement, as developed by R. L. Shreve for the Blackhawk slide, are now rather suspect.

The first part of a two-volume survey of rockslides and avalanches, this book
Davis), sensory systems (Wiersma and Roach), and neuronal plasticity and the modification of behaviour (Kandel).

In the final chapter, Kandel reviews recent evidence from his laboratory that habituation of the gill withdrawal reflex in Aplysia, which can last for a day or more, is due to a reduction in the mean number of quanta of transmitter released from sensory nerve terminals on to the gill motor neurones. Granted that habituation is a very simple form of learning, these experimen'ts nevertheless come close to providing the beginnings of a physiology of the engram.

Considered as a work of reference this book has its faults. The most serious is the inadequacy of the Index, which contains too few entries with any practical value and too many with none. Cross-indexing in the text is perfunctory, and is to chapters rather than to specific pages. Some but not all chapters have summaries. Reference lists are remarkably complete up to 1975-76.

All in all, this is a magnificent piece of scholarship; the American Physiological Society has put all neurobiologists greatly in its debt. Librarians and those for whom moral debts are more irksome than the kind bank managers write letters about will want to buy their copy at once.

T. V. P. Bliss

T. V. P. Bliss is a member of the Division of Neurophysiology and Neuropharma cology at the National Institute for Medical Research, London, UK.

deals with such natural phenomena. Volume 2 will contain the articles relating to engineering problems.

Besides the chapter dedicated to Heim and an introduction by B. Voigt and W. G. Pariseau, volume 1 contains sections on classic rockslides and avalanches (chapters 2-9); large-scale prehistoric mass movements (chapters 10-16); rock creep, scale effects and related questions (chapters 17-21); and mass movement of snow and ice (chapters 22-24); 833 pages costing $£ 50$ - and no index; that will be found in volume 2 .

The Blackhawk event gets an interesting chapter to itself, as do 13 other rockslides, and these chapters provide a very useful and readable set of histories. The apparent awkwardness of the sudden jump to principles, and to snow and ice problems, is probably caused by the fact that this is only half the complete work. The completed survey should be a valuable reference work but will presumably be beyond the means of individual buyers.

\section{J. Smalley}

I. J. Smalley is Lecturer in the Department of Civil Engineering at the University of Leeds, UK. 